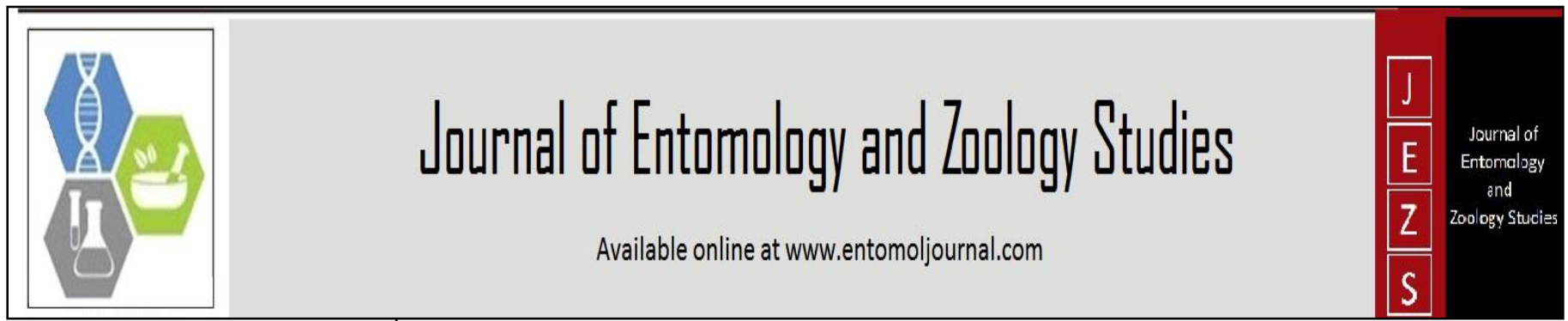

E-ISSN: 2320-7078

P-ISSN: 2349-6800

www.entomoljournal.com JEZS 2020; 8(4): 922-928 (C) $2020 \mathrm{JEZS}$

Received: 08-05-2020

Accepted: 10-06-2020

\section{Manu HN}

Department of Studies in Sericulture, University of Mysore, Manasa Gangothri, Mysore, Karnataka, India

\section{Prashanth J}

Department of Studies in

Sericulture, University of

Mysore, Manasa Gangothri,

Mysore, Karnataka, India

\section{Chaitra S}

Department of Studies in Sericulture, University of Mysore, Manasa Gangothri, Mysore, Karnataka, India

Jagadeeshkumar TS Department of Studies in Sericulture, University of Mysore, Manasa Gangothri, Mysore, Karnataka, India

Corresponding Author: Prashanth J

Department of Studies in Sericulture, University of Mysore, Manasa Gangothri, Mysore, Karnataka, India

\section{Evaluation of various parameters of consumption indices of the silkworm hybrids administered with cholesterol content during $5^{\text {th }}$ instar silkworm}

\author{
Manu HN, Prashanth J, Chaitra S and Jagadeeshkumar TS
}

DOI: https://doi.org/10.22271/j.ento.2020.v8.i4o.7236

\section{Abstract}

The ingesta and digesta of the silkworm hybrids treated with different doses of cholesterol during $5^{\text {th }}$ instar was evaluated, the maximum ingesta was recorded in $\mathrm{FC}_{1} \mathrm{X} \mathrm{FC}_{2}$ than $\mathrm{FC}_{4} \mathrm{X} \mathrm{FC}$ hybrid whereas, the digesta also showed a same trend as observed in ingesta, however the comparative evaluation of the digesta were found to be noticed always half of the ingesta. The efficiency of conversion of food ingested, efficiency of conversion of food digested and approximate digestibility enhances above the level of $50 \%$ the day1 of the $5^{\text {th }}$ instar till the day of spinning $\mathrm{FC}_{4} \mathrm{X} \mathrm{FC}$ hybrid, whereas the $\mathrm{FC}_{1} \mathrm{X} \mathrm{FC}_{2}$ hybrid exhibits the magnitude of changes not more than level of $50 \%$ throughout the $5^{\text {th }}$ instar larval periods. The consumption index, growth rate and co-efficient of metabolism of the silkworm hybrid treated with cholesterol during $5^{\text {th }}$ instar but the ratio falls within the range of $0-2$ in all the concentration of cholesterol but on $7^{\text {th }}$ day, the consumption index exceeds the ratio upto 9 at $0.1 \mathrm{M}$ concentration of cholesterol treatment.

Keywords: Consumption indices, Silkworm hybrids, Cholesterol content, Late age silkworms

\section{Introduction}

Sericulture is an art of science that deals with the production of raw silk by rearing of the silkworm. Silk is called as queen of textiles due to its glittering luster, softness, elegance, durability and tensile properties and is discovered in China between and 2600 and 2700 BC. Silk originating from the land of China as a natural fibrous substance and is obtained from pupal nests is cocoon spun by silkworm. The silk is prepared over all other type of fibers due to its remarkable properties like water absorbency, heat resistance, dyeing efficiency and luster. Factors mainly influence the physiology of insect are temperature and humidity. Despite of wide fluctuations in their surroundings, insects show a remarkable range of adoptions to fluctuating environmental conditions and maintain their internal temperature and water content within tolerable limits. Silkworm is one of the most domesticated insect, which produces luxuriant silk thread in the form of a cocoon by consuming mulberry leaves during larval period. The growth and development of the silkworm is greatly influenced by environmental conditions. The biological as well as cocoon- related characters are influenced by ambient temperature, rearing seasons, quality of mulberry leaf, and genetic constitution of silkworm strains. The temperature plays a vital role on the growth of silkworms. As the silkworms are cold-blooded insect, temperature will have a direct effect on various physiological activities. In general, the early instar larvae are resistant to high temperature which also helps in improving survival rate and manifestation of cocoon characters.

Cholesterol is a dominant sterol that accumulates in eggs regardless of dietary sterol components. The accumulation of sterol esters was higher in diapause than in non-diapause ovaries of silkworm ${ }^{[10]}$. Cholesterol is transformed from the fat body tissues to the eggs through lipophorin in a temperature dependent aqueous diffusion mode of action. $90 \%$ reduction in haemolymph cholesterol titers by dietary intervention brought about 10-20\% reduction in egg production in adult female locusta migratotia. In the eggs laid, ecdysteroid content varied and severe developmental abnormalities were observed. In view of the importance of the ecdysteroid derivatives in the larval growth the effects of exogenous cholesterol on a number of nutritive parameters of consumption indices and economic traits of the silkworm hybrids are taken up in the present investigation. 


\section{Materials and methods}

In the present study two productive double hybrids namely $\mathrm{FC}_{1} \mathrm{X} \mathrm{FC}_{2}$ and $\mathrm{FC}_{4} \mathrm{X} \mathrm{FC} 3$ were chosen and reared throughout the year under Indian conditions were utilized. Rearing was conducted as per the standard package and recommendation by providing healthy fresh leaves of $\mathrm{V}_{1}$ mulberry variety ${ }^{[12]}$. The feed utilization study was confined only to IV and $\mathrm{V}$ instar larva as $80-85 \%$ of the total leaf consumed in these instar. On consumption of IV and V instar silkworm larvae three replicates were separated from each batches of double hybrids and kept in normal temperature of $28-30^{\circ} \mathrm{C}$ and $80 \%$ humidity condition Known quantities of mulberry leaves were provided to silkworm thrice a day taking utmost care to maintain the leaf moisture content to the maximum possible extent.

Sample of mulberry leaves used for feeding was placed in separate tray as dummy for dry weight determination of ingesta. Additional larval batches of each hybrids were maintained in parallel to determine the dry weight and subsequent determination of daily increment in larval weight [14]. The healthy larvae were unhealthy and dead larvae were removed. The litter was selected carefully on subsequent days of feeding. The excreta and left over leaf in the litter were manually separated and dried in an oven to a constant weight. Observation on dry weight of left over leaf, excreta, larval weight gain, cocoon weight and shell weight were recorded for all the replications of each treatment.

From these data, nutritional indices like, ingesta, digesta, approximate digestibility percentage (AD \%), efficiency of conversion of ingested food (ECI), efficiency of conversion of digested food into body substance (ECD), consumption index (CI), growth rate and coefficient metabolism of the selected bivoltine $\mathrm{FC}_{1} \mathrm{X} \quad \mathrm{FC}_{2}$ and $\mathrm{FC}_{4} \mathrm{X} \quad \mathrm{FC}_{3}$, a newly evolved productive double hybrids were utilized in the present investigation. The freshly moulted $4^{\text {th }}$ and $5^{\text {th }}$ instar silkworm larvae were grouped into four batches, each batch having three replication of 100 silkworm and maintained constant of temperature $25 \pm 1^{\circ} \mathrm{C}$ and $70 \pm 5 \%$ Relative humidity during the silkworm rearing.

\section{Cholesterol treatment}

Cholesterol (Procured from Sisco Research Laboratories Ltd. Mumbai, India) was dissolved in small quantity of chloroform and diluted with ethyl alcohol to $0.01,0.1$ and $0.5 \mathrm{M}$ concentrations. The mulberry leaf was smeared on the ventral surface with $1 \mathrm{ml}$ solution and after drying fed to $4^{\text {th }}$ and $5^{\text {th }}$ instars larval stage in separate batches. The cholesterol smeared leaf was offered first on the day of treatment, and after the leaf was fed upon completely to the group of 100 larvae. The batch-I larvae are considered as carrier control as the larvae fed with normal mulberry leaf sprayed with ethyl alcohol aliquots. However, the other three batches containing 100 larvae each (in three replicates) were fed on the three doses of uniformly smeared cholesterol treated leaves on $1^{\text {st }}$, $3^{\text {rd }}$ and $5^{\text {th }}$ day. Cholesterol supplemented leaf was provided during the first feeding on the day of treatment. A total of three feeding are provided every day.

\section{Nutritional indices}

Fresh leaves of mulberry were cut through midrib into two symmetrical halves, one half was used to find out the moisture content of the leaves and the other half was weighed and smeared with known volume of cholesterol. Equal and known quantity of leaf was offered to all silkworm batches, taking into consideration the consumption level on each day of $4^{\text {th }}$ and $5^{\text {th }}$ instars larval development. The left over leaf of the excreta were dried in a hot air oven at $80^{\circ} \mathrm{C}$ till constant weight and the values were recorded. The initial and final wet and dry weights of larvae were recorded every day. Daily food consumption and utilization were recorded by following the standard gravimetric method. The dry weights of leaf ingested and digested by each larva were calculated and the nutritional indices such as approximate digestibility (AD), efficiency of converting leaf ingested (ECI) and leaf digested (ECD) into larval body substance, consumption index (CI), growth rate (GR) and coefficient metabolism (COM) were calculated as per the empirical formulae provided are as follows ${ }^{[19]}$.

\section{Leaf ingested}

Leaf ingested is the amount of leaf consumed by the larva for the specific period.

Leaf ingested $=$ dry weight of the leaf offered - dry weight of left over leaf.

\section{Leaf digested:}

Leaf digested is the amount of leaf assimilated by the larva for the specific period.

Leaf digested $=$ dry weight of the leaf ingested -dry weight of excreta

\section{Efficiency of conversion of ingested food (ECI):}

Efficiency of conversion of ingested food into body substance is the percentage of ingested food contributing to weight gain the larva

$\mathrm{ECI}=\frac{\text { Dry weight gained by larva }}{\text { Dry weight of food ingested }} \times 100$

\section{Efficiency of conversion of digested food into body substance (ECD)}

Efficiency of conversion of digested food into body substance is the percentage of digested food in dry weight contributing to weight gain the larva

$\mathrm{ECD}=\frac{\text { Dry weight gained by larva }}{\text { Dry weight of food digested }} \times 100$

\section{Approximate digestibility (AD \%)}

Approximate digestibility is the percentage of ingested food digested and absorbed

$$
\mathrm{AD}=\frac{\text { Weight of food digested }}{\text { Weight of food ingested }} \times 100
$$

\section{Consumption index (CI)}

Consumption index is the quantity of food consumed for the observe increase in the larval

$$
\mathrm{CI}=\frac{\text { Dry weight of food consumed }}{\text { Duration of feeding period } \mathrm{x} \text { mean dry weight of larva during feeding period }}
$$


Growth rate

Growth rate is the unit weight gain for the day

$$
\mathrm{GR}=\frac{\text { Dry weight gain of larva during feeding period }}{\text { Duration of feeding period } \mathrm{x} \text { Mean dry weight of larva during feeding period }}
$$

\section{Coefficient of metabolism}

Coefficient of metabolism is the fraction of digested food required for metabolic activity of produce the observed weight gain for the day

$$
\mathrm{COM}=\frac{\text { weight } \text { of food digested }- \text { increase in weight of larva }}{\text { Weight of food digested }}
$$

\section{Results and discussion}

A nutritional indices of cholesterol treated $\mathrm{FC}_{1} \mathrm{X} \mathrm{FC} 2$ and $\mathrm{FC}_{4}$ $\mathrm{X} \mathrm{FC}_{3}$ hybrids during $5^{\text {th }}$ instar was evaluated with the reference to ingesta and digesta, the day wise from 1 to $7^{\text {th }}$ day. The maximum rate of ingesta represents only to control batches. Whereas cholesterol treated at different concentration of $0.01,0.1$ and $0.5 \mathrm{M}$ showed a relative decrease from the lower concentration to higher concentration, but on $5^{\text {th }}$ day onwards the rate of ingestion of the food is doubled compare to previous days at the same time of ingesta also responded in such a way from day 1 to day 7 , and a consistent level of decreases were observed under different concentration of cholesterol administered silkworm compare to respective control for all the days. ECI and ECD are to utilization parameters of the nutritional indices for a day to day increase and multiplied till the day of spinning up to 81.14 at $0.1 \mathrm{M}$ on $7^{\text {th }}$ day as far as ECI is concerned. Parallely ECD also very important parameter reflects on the efficiency of food digestion leads to the improvement in the larval characters. It is noticed that on day 1 the ECD 6.00 on $7^{\text {th }}$ day 695 almost 700 times multiplied it is an indicator for the mobilization of increased level of ECD it can be magnified in terms of expression of the economic parameters. However the ECI and ECD are the essential indices to perform better in the manifestation of economic characters, similarly approximate digestibility represents percentage in all the days during $5^{\text {th }}$ instar including control and treated batches of different concentration of cholesterol administered in $\mathrm{FC}_{1} \mathrm{X} \quad \mathrm{FC}_{2}$ hybrid, the level of digestibility is very high and peak on first day subsequently it is negatively related in all the remaining days on $7^{\text {th }}$ day, the ECI and ECD are parallely equal to the proportion of conversion of ingesta and digesta but invertionaly proportional with each other in ECI and ECD. There are three more factors namely, CI, GR and COM which were related to be an important parameters represented in the ratio and the consumption index day first is maximized at the control batches compare to the different concentration. The $2^{\text {nd }}$ day onwards the rapid decline in the consumption index when the days are advanced till the day of spinning on $7^{\text {th }}$ day. The lowest was recorded $(0.55)$ at $0.5 \mathrm{M}$, whereas the growth rate will be one of the universal growth phenomena are exhibited based on the food utilization parameters. Therefore it is a constant on day 1 to $7^{\text {th }}$ day. The COM is collective quantum of the conversion of metabolic energy necessarily facilitate all the physiological condition, manifestation and utilization. The biochemical events of successive cellular and sub cellular functions with reference to $\mathrm{FC}_{1} \mathrm{XFC}_{2}$ hybrids.

The $\mathrm{FC}_{4} \mathrm{X} \mathrm{FC}_{3}$ potential bivoltine hybrid was utilized to carry out the assessment of nutritional indices and it is better responded a consistent efficiency in the ingesta and digesta with a same trend as observed in ingesta and digesta of $\mathrm{FC}_{1} \mathrm{X}$ $\mathrm{FC}_{2}$ hybrids. The remaining parameters of ECI, ECD, and $\mathrm{AD} \%, \mathrm{CI}, \mathrm{GR}$ and $\mathrm{COM}$ were represents a marginal differences in a day wise treatments and but the trend has been observed as most similar in maximum possibilities under the investigation of nutritional indices.

The silkworm, Bombyx mori is a monophagous lepidopteran insect which has been domesticated for more than five thousand years. The physiology of silkworm has been studied extensively due to the economic importance of silk production over the centuries. Further studies on food preferences and optimal nutrient levels for maximum larval growth and silk production eventually led to the development of an artificial diet. Today, Bombyx mori can be raised entirely on artificial diet from the first to the last larval instars. Mulberry leaves suitable as food for silkworm must contain several chemical constituents such as water $(80 \%)$, proteins $(27 \%)$ and carbohydrates $(11 \%)$, other extracts, mineral matters, vitamins etc. and at the same time, they must have the favorable physical features such as suitable tenderness, thickness and tightness, in order to be eaten by silkworms [11]. Mulberry (Morus species) leaf is the sole food and source of nutrition for the growth and development of silkworm due to the presence of phagostimulent as a morin.

Recently, much research has been done on the diet supplementation of mulberry leaves fed to silkworm. This supplementation includes vitamins such as ascorbic acid, thiamine, niacin, folic acid, multi-vitamins and vitamin $C^{[16 \text {, }}$ $18,6,7,1]$. Although some of the compounds have shown significant results, enrichment has not always caused the improvement of biological characteristics of the silkworm. They have reported the yield decrease, when ascorbic acid concentration is enhanced in silkworm diet ${ }^{[7]}$. Dietary supplementation of copper sulphate, nickel chloride and potassium iodide increased the physiological parameters of the silkworm ${ }^{[13]}$. Multi-vitamin and mineral compounds could increase the food intake, growth and conversion efficiency of the silkworm. Nutrition is an important growth regulating factor in the silkworm. It has been reported that the vitamins of B-complex group and certain essential sugars, proteins, amino acids, minerals etc. are responsible for the proper growth and development of the silkworm ${ }^{[9]}$.

Feeding patterns have also been observed in other lepidopteron insects such as the tobacco hornworm, Manduca sexta $^{[5,4]}$, the woolly bear caterpillar, Grammia geneura ${ }^{[3]}$ and the corn earworm, Helicoverpa armigera ${ }^{[2]}$. In addition, feeding patterns of Manduca larvae raised on artificial diet were found to be different from those of caterpillars fed plant leaves ${ }^{[4]}$. The quality and quantity of the mulberry leaves fed during rearing, decide the success of the silkworm crop. Hence, the choice of mulberry leaves suitable for healthy growth of silkworm is one of the most important factors in sericulture. It feeds continuously during five instars of larval period to spin cocoon. Cocoon characters both quantitative as well as qualitative, depends largely on the quality and quantity of leaves ${ }^{[11,1]}$. The silkworm larvae are attracted by three stimulants in mulberry leaves viz., the attractant, biting 
factor and swallowing factor ${ }^{[8]}$. Leaf consumption directly affects the silk producing capacity of the silkworm. The leaf consumption influenced the body weight which in turn influences the silk output. Therefore, a very simple and clear piece of logic to boost the production of the silk, improved quality of leaf or mulberry variety has to be used for silkworm rearing. Thus, for each instar, the increase in fresh and dry weights of the larvae, fresh and dry weights of food eaten and digested and dry weight of faeces produced were recorded ${ }^{[17]}$. There is a need to recognize and integrate the physiological and nutritional requirements of the silkworm hybrids under ecological conditions for silkworm breeding and management programmes to make them need-based ${ }^{[15]}$.

A dose dependent decrease during the active growth phase suggests reducing feeding response when cholesterol supplemented mulberry leaf was provided for ingestion. Phytophagous insect do not selectively absorb when a mixture of sterol was provided for ingestion. Sterol absorption takes place across midgut tissue in phytophagous insect. Insect do not have bile salts that play a significant role in sterol absorption in vertebrates. The sterol was packed as mixed micelle with phospholipids and are observed into the mid gut epithelial cells in insects. Dietary lipids enhance the efficiency of sterol uptake in the glass moth, crambus tricestus.

The nutritive value of the leaf increases by cholesterol supplementation leading to lower levels of its ingestion and digestion. The relatively higher decreases of leaf ingested on $5^{\text {th }}$ and $6^{\text {th }}$ day is an account of the cumulative effect of absorbing higher levels of carbon resources during the preceding days of larval development. The relatively higher decreases observed at higher doses brought greater reduction in the quality of leaf ingested on $5^{\text {th }}$ and $6^{\text {th }}$ day. ECI increases significantly during active growth stage in control. ECI showed a higher increase of larvae fed upon cholesterol supplemented leaf. The increases in ECI were higher at higher doses of cholesterol. ECI reflects the ability of the silkworm to utilize ingested leaf for weight gain. Higher ECI is observed when greater proportion of ingested food is incorporated into body substance and lesser metabolic energy utilized to convert leaf substance into the body constituents of the silkworm. Cholesterol association brought about easy conversion of the leaf constituents of the silkworm body substance at reduced metabolic cast.

ECD values were higher during active growth and cholesterol supplementation increased further ECD values in silkworms. Also, relatively higher values of ECD were observed at higher levels of cholesterol application. ECD depends on the levels of the food intake and its nutritive value. ECD depends less on the digestibility of the nutritive food but more on the metabolic cost of growth and maintenance. Higher ECD values suggest higher food efficiency and lower cost of maintenance. Approximate digestibility is the proportion of the ingested food and digested and absorbed. Approximate digestibility depends on a number of factors like rate and quantity of food intake, retention time in the mid gut, nature and efficiency of digestive enzymes and digestibility of the complex nutritive components in the diet. The Approximate digestibility is a relatively high on day1 due to gut emptiness during preceding moulting stage and lower rates of consumption. The Approximate digestibility falls significantly on $2^{\text {nd }}$ due to increased food intake and faster gut movement leading to lesser retention time. Approximate digestibility improves significantly during active growth periods (days 3-
6) despite higher level of consumption by increased efficiency of digestive enzymes, which are induced to greater secretion by secretagogues mechanism. The Approximate digestibility decreased consistently in silkworm fed upon cholesterolsupplemented leaf. Approximate digestibility is not a reliable estimate as metabolic wastes like uric acid are added to the undigested food and are not taken into account.

Consumption index increases significantly till mid growth period after which it falls consistently to reach minimal levels on $6^{\text {th }}$ day of larval development. Consumption indices were lower in silkworm consuming cholesterol supplemented leaves, which means less leaf is required to produce a unit gain in the larval weight. Cholesterol supplementation presumably improves the nutritive value of leaf by its own absorption and increases in the absorption of essential nutrients. The growth rate increases consistently in control from day 1 to attain maximum level on $4^{\text {th }}$ day after which it drops successively to attain minimal level on $6^{\text {th }}$ day. The growth rate is cholesterol treated silkworm followed the same pattern through the values tend to be higher than the control. The higher growth rate despite lower Consumption could be attributed to lower levels of Coefficient of metabolism observed in silkworms fed with cholesterol treated leaf. Lower Coefficient of metabolism observed in silkworm fed with cholesterol treated leaf results from lower energy cost for maintenance and growth. Significantly higher levels of COM in control and treated silkworms on day 6 reflect the metabolic casts of silk synthesis.

A number of economic characters that provide estimates of silkworm growth, silk biosynthesis, silk and egg production are determined in treated larvae to evaluate the impact of cholesterol treatment on them. Larval duration was significantly reduced in all the treatments through the difference between the treatments was not significant. Both feeding duration and maturation period were reduced on cholesterol treatments. The reduction in feeding duration is caused by increased feed conversion efficiency due to higher titers of metabolic hormones in the circulating haemolymph. Higher basal vessels of ecdysteroids increased the secretary activity of corpora allata. Maturation time was reduced on account of precursor role of cholesterol for ecdysteroid synthesis.

Higher percentage of pupation observed in cholesterol treated larvae supports synchronization of spinning activity by significant reduction in maturation time. Phytosterols from diverse resources have been used to synchronize spinning activity in commercial silkworm rearing. Better feed conversion efficiency results in 5-9\% increase in larval weight despite lower consumption index. The differences in the larval weight between treatments did not significant impact on silk biosynthesis as evident from higher silk gland weights and higher silk gland somatic indices at 0.01 and $0.1 \mathrm{M}$ cholesterol concentrations. The roles of ecdysteroids in silk biosynthesis have been well established. Application of exogenous sterol compounds from plant sources through last feeding hastens maturation process by increasing the synthesis and secretion of silk in silk gland. Higher shell weight and shell ratio at 0.01 and $0.1 \mathrm{M}$ cholesterol concentrations corroborate steroid stimulated silk synthesis and secretion.

Cholesterol provides indirect supports to silk biosynthesis in its precursor role towards ecdysteroids synthesis but is directly involved in egg development. Cholesterol is dominant sterol that accumulates in eggs. Cholesterol is esterifies and 
stored in higher quantities in diapauses eggs than in nondiapauses eggs. Cholesterol free diets do not significantly affect egg production in adult female Locusta migratoria but embryonic development and rate of hatching are severely altered by low ecdysteroids levels. Though cholesterol free diets may not affect egg production in lepidopteran insects, cholesterol supplemented diet has significantly improved the fecundity from in control of 0.1 and $0.01 \mathrm{M}$ cholesterol concentrations in Bombyx mori. Cholesterol is essential for normal embryonic development through its supports for ecdysteroid synthesis and its involvement in the formation of new membrane in association with phospholipids.

Table 1: Food consumption and utilization of $\mathrm{FC}_{1} \mathrm{X} \mathrm{FC}_{2}$ silkworm hybrid treated with three doses of cholesterol during fifth instar (Each value is mean of three observations $\pm \mathrm{SD}$ )

\begin{tabular}{|c|c|c|c|c|c|c|c|}
\hline \multirow{2}{*}{ Days } & \multirow{2}{*}{ Conc. } & Fresh larval wt. (g) & Dry larval wt. (g) & Fresh left over leaf (g) & Dry left over leaf (g) & Fresh litter $(\mathrm{g})$ & Dry litter $(g)$ \\
\hline & & Mean \pm SD & Mean \pm SD & Mean \pm SD & Mean \pm SD & Mean \pm SD & Mean \pm SD \\
\hline \multirow{4}{*}{1} & Control & $0.646 \pm 0.002$ & $1.173 \pm 0.006$ & $20.393 \pm 0.525$ & $10.223 \pm 0.090$ & $2.263 \pm 0.015$ & $1.930 \pm 0.010$ \\
\hline & $0.01 \mathrm{M}$ & $0.724 \pm 0.021$ & $1.250 \pm 0.020$ & $19.143 \pm 0.942$ & $8.617 \pm 0.087 \mathrm{NS}$ & $2.890 \pm 0.373$ & $2.373 \pm 0.298$ \\
\hline & $0.1 \mathrm{M}$ & $0.739 \pm 0.047$ & $1.327 \pm 0.110$ & $24.713 \pm 0.301 *$ & $12.520 \pm 0.442 *$ & $3.037 \pm 0.134$ & $2.787 \pm 0.087$ \\
\hline & $0.5 \mathrm{M}$ & $0.693 \pm 0.022$ & $1.370 \pm 0.010$ & $18.693 \pm 0.164 \mathrm{NS}$ & $8.817 \pm 0.076$ & $2.470 \pm 0.494$ & $2.173 \pm 0.283$ \\
\hline \multirow{4}{*}{2} & Control & $1.044 \pm 0.006$ & $3.367 \pm 0.012$ & $16.310 \pm 0.036$ & $7.827 \pm 0.735$ & $5.890 \pm 0.168$ & $4.440 \pm 0.498$ \\
\hline & $0.01 \mathrm{M}$ & $1.116 \pm 0.060$ & $3.400 \pm 0.010$ & $16.803 \pm 0.870$ & $8.343 \pm 0.159$ & $6.147 \pm 0.083$ & $4.283 \pm 0.241$ \\
\hline & $0.1 \mathrm{M}$ & $1.119 \pm 0.095$ & $3.350 \pm 0.010$ & $17.243 \pm 0.155$ & $8.630 \pm 0.132$ & $6.130 \pm 0.468$ & $4.767 \pm 0.432$ \\
\hline & $0.5 \mathrm{M}$ & $1.050 \pm 0.021$ & $3.513 \pm 0.015$ & $17.780 \pm 0.148$ & $6.663 \pm 0.015$ & $5.953 \pm 0.144$ & $4.373 \pm 0.050$ \\
\hline \multirow{4}{*}{3} & Control & $1.372 \pm 0.003$ & $3.773 \pm 0.021$ & $9.863 \pm 0.015$ & $6.943 \pm 0.068$ & $6.707 \pm 0.083$ & $5.870 \pm 0.010$ \\
\hline & $0.01 \mathrm{M}$ & $1.350 \pm 0.032$ & $3.780 \pm 0.020$ & $13.023 \pm 0.348$ & $7.283 \pm 0.242$ & $6.780 \pm 0.030$ & $5.570 \pm 0.252$ \\
\hline & $0.1 \mathrm{M}$ & $1.410 \pm 0.067$ & $3.770 \pm 0.026$ & $15.833 \pm 0.104$ & $9.330 \pm 0.754$ & $6.500 \pm 0.209$ & $4.877 \pm 0.015$ \\
\hline & $0.5 \mathrm{M}$ & $1.323 \pm 0.059$ & $3.863 \pm 0.025$ & $14.560 \pm 0.398$ & $5.157 \pm 0.211$ & $6.337 \pm 0.031$ & $5.110 \pm 0.235$ \\
\hline \multirow{4}{*}{4} & Control & $1.611 \pm 0.001$ & $5.963 \pm 0.015$ & $9.280 \pm 0.026$ & $5.923 \pm 0.081$ & $7.787 \pm 0.006$ & $5.290 \pm 0.061$ \\
\hline & $0.01 \mathrm{M}$ & $1.695 \pm 0.048 *$ & $6.067 \pm 0.076^{*}$ & $10.317 \pm 0.376$ & $6.377 \pm 0.240$ & $8.750 \pm 0.218^{*}$ & $6.827 \pm 0.172 *$ \\
\hline & $0.1 \mathrm{M}$ & $1.573 \pm 0.036$ & $5.970 \pm 0.010$ & $12.027 \pm 0.162^{*}$ & $6.130 \pm 0.147$ & $8.280 \pm 0.114$ & $6.593 \pm 0.187$ \\
\hline & $0.5 \mathrm{M}$ & $1.608 \pm 0.021$ & $6.063 \pm 0.090$ & $10.597 \pm 0.472$ & $6.130 \pm 0.147$ & $7.627 \pm 0.821$ & $6.600 \pm 0.202$ \\
\hline
\end{tabular}

*significant at $(0.05 \%)$ of probability

NS=Non significant

Table 2: Food consumption and utilization of $\mathrm{FC}_{1} \mathrm{X} \mathrm{FC} 2$ silkworm hybrid treated with three doses of cholesterol during fifth instar (Each value is mean of three observations \pm SD)

\begin{tabular}{|c|c|c|c|c|c|c|c|}
\hline \multirow{2}{*}{ Days } & \multirow{2}{*}{ Conc. } & Fresh larval wt. (g) & Dry larval wt. (g) & Fresh left over leaf (g) & Dry left over leaf (g) & Fresh litter (g) & Dry litter (g) \\
\hline & & Mean \pm SD & Mean \pm SD & Mean \pm SD & Mean \pm SD & Mean \pm SD & Mean \pm SD \\
\hline \multirow{4}{*}{5} & Control & $1.927 \pm 0.006$ & $6.577 \pm 0.015$ & $13.200 \pm 0.100$ & $7.033 \pm 0.015$ & $8.067 \pm 0.521$ & $14.957 \pm 0.067$ \\
\hline & $0.01 \mathrm{M}$ & $2.084 \pm 0.123$ & $6.653 \pm 0.031$ & $16.817 \pm 0.251$ & $8.393 \pm 0.123$ & $8.250 \pm 0.250$ & $6.447 \pm 0.185$ \\
\hline & $0.1 \mathrm{M}$ & $2.131 \pm 0.071$ & $6.673 \pm 0.006$ & $20.603 \pm 0.365 *$ & $10.110 \pm 0.095^{*}$ & $7.570 \pm 0.367 \mathrm{NS}$ & $5.827 \pm 0.465$ \\
\hline & $0.5 \mathrm{M}$ & $1.929 \pm 0.025$ & $6.640 \pm 0.036$ & $20.383 \pm 0.500$ & $10.033 \pm 0.550$ & $8.447 \pm 0.561$ & $5.507 \pm 0.446 \mathrm{NS}$ \\
\hline \multirow{4}{*}{6} & Control & $2.327 \pm 0.023$ & $7.877 \pm 0.015$ & $11.723 \pm 0.015$ & $6.867 \pm 0.021$ & $10.517 \pm 0.059$ & $6.903 \pm 0.765$ \\
\hline & $0.01 \mathrm{M}$ & $2.466 \pm 0.072$ & $8.190 \pm 0.010$ & $13.030 \pm 0.729$ & $7.683 \pm 0.208$ & $9.170 \pm 0.056 \mathrm{NS}$ & $6.763 \pm 0.752$ \\
\hline & $0.1 \mathrm{M}$ & $2.558 \pm 0.095$ & $8.213 \pm 0.015$ & $13.320 \pm 0.962$ & $7.210 \pm 0.417$ & $11.107 \pm 0.647$ & $7.873 \pm 0.631$ \\
\hline & $0.5 \mathrm{M}$ & $2.506 \pm 0.344$ & $8.187 \pm 0.163$ & $14.623 \pm 0.261$ & $8.167 \pm 0.256$ & $10.260 \pm 0.036$ & $9.060 \pm 0.122$ \\
\hline \multirow{4}{*}{7} & Control & $2.401 \pm 0.062$ & $8.700 \pm 0.100$ & $11.963 \pm 0.015$ & $6.963 \pm 0.015$ & $13.313 \pm 0.021$ & $10.650 \pm 0.226$ \\
\hline & $0.01 \mathrm{M}$ & $2.689 \pm 0.185^{*}$ & $8.853 \pm 0.031 *$ & $13.907 \pm 0.774$ & $8.697 \pm 0.598$ & $14.317 \pm 0.253$ & $13.410 \pm 0.321 *$ \\
\hline & $0.1 \mathrm{M}$ & $2.512 \pm 0.047$ & $8.830 \pm 0.010$ & $11.737 \pm \pm 0.456$ & $6.410 \pm 0.070$ & $17.510 \pm 0.191 *$ & $11.890 \pm 0.017$ \\
\hline & $0.5 \mathrm{M}$ & $2.320 \pm 0.026$ & $8.830 \pm 0.010$ & $12.460 \pm 0.035$ & $7.973 \pm 0.021$ & $15.357 \pm 0.552$ & $11.413 \pm 0.153$ \\
\hline
\end{tabular}

*significant at $(0.05 \%)$ of probability

$\mathrm{NS}=$ Non significant

Table 3: Food consumption and utilization of $\mathrm{FC}_{4} \mathrm{X} \mathrm{FC}_{3}$ silkworm hybrid treated with three doses of cholesterol during fifth instar (Each value is mean of three observations $\pm \mathrm{SD}$ )

\begin{tabular}{|c|c|c|c|c|c|c|c|}
\hline \multirow{2}{*}{ Days } & \multirow{2}{*}{ Conc. } & Fresh larval wt. (g) & Dry larval wt. (g) & Fresh left over leaf (g) & Dry left over leaf (g) & Fresh litter (g) & Dry litter (g) \\
\hline & & Mean \pm SD & Mean \pm SD & Mean \pm SD & Mean \pm SD & Mean \pm SD & Mean \pm SD \\
\hline \multirow{4}{*}{1} & Control & $0.689 \pm 0.002$ & $1.253 \pm 0.051$ & $20.840 \pm 0.226$ & $10.437 \pm 0.115$ & $2.340 \pm 0.026$ & $1.967 \pm 0.015$ \\
\hline & $0.01 \mathrm{M}$ & $0.733 \pm 0.041$ & $1.267 \pm 0.021$ & $21.430 \pm 0.299$ & $11.497 \pm 0.101$ & $2.927 \pm 0.422$ & $2.523 \pm 0.445$ \\
\hline & $0.1 \mathrm{M}$ & $0.720 \pm 0.046$ & $1.270 \pm 0.020$ & $22.683 \pm 0.718$ & $11.660 \pm 0.859 *$ & $2.723 \pm 0.263$ & $2.317 \pm 0.275$ \\
\hline & $0.5 \mathrm{M}$ & $0.694 \pm 0.015$ & $1.277 \pm 0.006$ & $22.950 \pm 0.044^{*}$ & $11.617 \pm 0.193$ & $2.870 \pm 0.046$ & $2.520 \pm 0.040$ \\
\hline \multirow{4}{*}{2} & Control & $1.037 \pm 0.023$ & $3.340 \pm 0.020$ & $16.210 \pm 0.185$ & $6.950 \pm 0.069$ & $5.827 \pm 0.045$ & $4.043 \pm 0.021$ \\
\hline & $0.01 \mathrm{M}$ & $1.110 \pm 0.076$ & $3.370 \pm 0.020$ & $17.920 \pm 0.883$ & $8.617 \pm 0.284$ & $5.517 \pm 0.356$ & $4.337 \pm 0.119$ \\
\hline & $0.1 \mathrm{M}$ & $1.024 \pm 0.067$ & $3.337 \pm 0.021$ & $17.460 \pm 0.684$ & $9.083 \pm 0.154$ & $5.413 \pm 0.117$ & $4.297 \pm 0.071$ \\
\hline & $0.5 \mathrm{M}$ & $1.116 \pm 0.074$ & $3.383 \pm 0.015$ & $17.363 \pm 0.682$ & $8.687 \pm 0.714$ & $5.300 \pm 0.355 \mathrm{NS}$ & $4.397 \pm 0.362$ \\
\hline \multirow{4}{*}{3} & Control & $1.281 \pm 0.039$ & $3.410 \pm 0.010$ & $10.247 \pm 0.047$ & $5.180 \pm 0.052$ & $13.157 \pm 0.121$ & $5.453 \pm 0.064$ \\
\hline & $0.01 \mathrm{M}$ & $1.284 \pm 0.026$ & $3.527 \pm 0.021$ & $15.553 \pm 0.631$ & $7.907 \pm 0.325$ & $12.723 \pm 0.102 *$ & $4.530 \pm 0.026$ \\
\hline & $0.1 \mathrm{M}$ & $1.319 \pm 0.119$ & $3.553 \pm 0.031$ & $19.070 \pm 0.488$ & $9.453 \pm 0.187$ & $12.010 \pm 0.572$ & $4.440 \pm 0.182$ \\
\hline & $0.5 \mathrm{M}$ & $1.466 \pm 0.028$ & $3.533 \pm 0.032$ & $18.870 \pm 0.036$ & $9.827 \pm 0.047$ & $12.280 \pm 0.030$ & $4.543 \pm 0.029$ \\
\hline \multirow{4}{*}{4} & Control & $1.610 \pm 0.011$ & $5.960 \pm 0.020$ & $9.340 \pm 0.142$ & $5.583 \pm 0.585$ & $7.887 \pm 0.095$ & $5.420 \pm 0.092$ \\
\hline & $0.01 \mathrm{M}$ & $1.748 \pm 0.137^{*}$ & $6.093 \pm 0.083$ & $9.777 \pm 0.178$ & $6.023 \pm 0.726$ & $8.870 \pm 0.582$ & $6.917 \pm 0.517 *$ \\
\hline & $0.1 \mathrm{M}$ & $1.642 \pm 0.047$ & $5.917 \pm 0.361$ & $12.843 \pm 0.103$ & $6.550 \pm 0.270$ & $7.780 \pm 0.062$ & $6.023 \pm 0.025$ \\
\hline & $0.5 \mathrm{M}$ & $1.658 \pm 0.100$ & $6.147 \pm 0.035^{*}$ & $11.733 \pm 0.873$ & $5.727 \pm 0.645 \mathrm{NS}$ & $7.987 \pm 0.023$ & $6.343 \pm 0.025$ \\
\hline
\end{tabular}

*significant at $(0.05 \%)$ of probability

$\mathrm{NS}=$ Non significant 
Table 4: Food consumption and utilization of $\mathrm{FC}_{4} \mathrm{X} \mathrm{FC}_{3}$ silkworm hybrid treated with three doses of cholesterol during $5^{\text {th }}$ instar (Each value is mean of three observations $\pm \mathrm{SD}$ )

\begin{tabular}{|c|c|c|c|c|c|c|c|}
\hline \multirow{2}{*}{ Days } & \multirow{2}{*}{ Conc. } & Fresh larval wt. (g) & Dry larval wt. (g) & Fresh left over leaf (g) & Dry left over leaf (g) & Fresh litter $(\mathrm{g})$ & Dry litter (g) \\
\hline & & Mean $\pm \mathrm{SD}$ & Mean \pm SD & Mean \pm SD & Mean \pm SD & Mean \pm SD & Mean \pm SD \\
\hline \multirow{4}{*}{5} & Control & $1.901 \pm 0.012$ & $6.277 \pm 0.032$ & $12.720 \pm 0.128$ & $6.170 \pm 0.053$ & $8.510 \pm 0.026$ & $5.103 \pm 0.015$ \\
\hline & $0.01 \mathrm{M}$ & $2.196 \pm 0.097$ & $6.313 \pm 0.021$ & $19.657 \pm 0.304$ & $10.700 \pm 0.528$ & $8.860 \pm 0.494$ & $6.870 \pm 0.477$ \\
\hline & $0.1 \mathrm{M}$ & $1.913 \pm 0.024$ & $6.247 \pm 0.006$ & $20.197 \pm 0.186$ & $10.503 \pm 0.067$ & $8.650 \pm 0.090$ & $7.023 \pm 0.078$ \\
\hline & $0.5 \mathrm{M}$ & $2.101 \pm 0.187$ & $6.287 \pm 0.042$ & $25.023 \pm 0.862 *$ & $12.477 \pm 0.051 *$ & $7.563 \pm 0.705 \mathrm{NS}$ & $5.833 \pm 0.817$ \\
\hline \multirow{4}{*}{6} & Control & $2.299 \pm 0.067$ & $7.847 \pm 0.067$ & $11.860 \pm 0.141$ & $6.530 \pm 0.310$ & $10.350 \pm 0.100$ & $7.733 \pm 0.072$ \\
\hline & $0.01 \mathrm{M}$ & $2.521 \pm 0.209$ & $7.933 \pm 0.031$ & $14.513 \pm 0.700$ & $6.587 \pm 0.787$ & $11.520 \pm 0.122$ & $7.527 \pm 0.604$ \\
\hline & $0.1 \mathrm{M}$ & $2.284 \pm 0.240$ & $7.923 \pm 0.025$ & $16.560 \pm 0.850$ & $6.573 \pm 0.973$ & $10.007 \pm 0.405$ & $6.947 \pm 0.059 \mathrm{NS}$ \\
\hline & $0.5 \mathrm{M}$ & $2.428 \pm 0.046$ & $7.980 \pm 0.030$ & $13.587 \pm 0.068$ & $7.230 \pm 0.082$ & $10.933 \pm 0.592$ & $7.680 \pm 0.598$ \\
\hline \multirow{4}{*}{7} & Control & $2.401 \pm 0.070$ & $8.823 \pm 0.025$ & $11.530 \pm 0.436$ & $6.977 \pm 0.015$ & $13.233 \pm 0.051$ & $8.920 \pm 0.053$ \\
\hline & $0.01 \mathrm{M}$ & $2.440 \pm 0.022$ & $8.837 \pm 0.006$ & $11.613 \pm 0.906$ & $8.707 \pm 0.219$ & $15.177 \pm 0.643$ & $13.023 \pm 0.067$ \\
\hline & $0.1 \mathrm{M}$ & $2.449 \pm 0.021$ & $8.847 \pm 0.006$ & $13.627 \pm 0.908$ & $8.127 \pm 0.025$ & $14.540 \pm 0.616$ & $10.510 \pm 0.046$ \\
\hline & $0.5 \mathrm{M}$ & $2.580 \pm 0.061 *$ & $8.870 \pm 0.010 *$ & $13.360 \pm 0.070 \mathrm{NS}$ & $8.630 \pm 0.468$ & $16.530 \pm 0.118^{*}$ & $12.377 \pm 0.310 *$ \\
\hline
\end{tabular}

*significant at $(0.05 \%)$ of probability

$\mathrm{NS}=$ Non significant

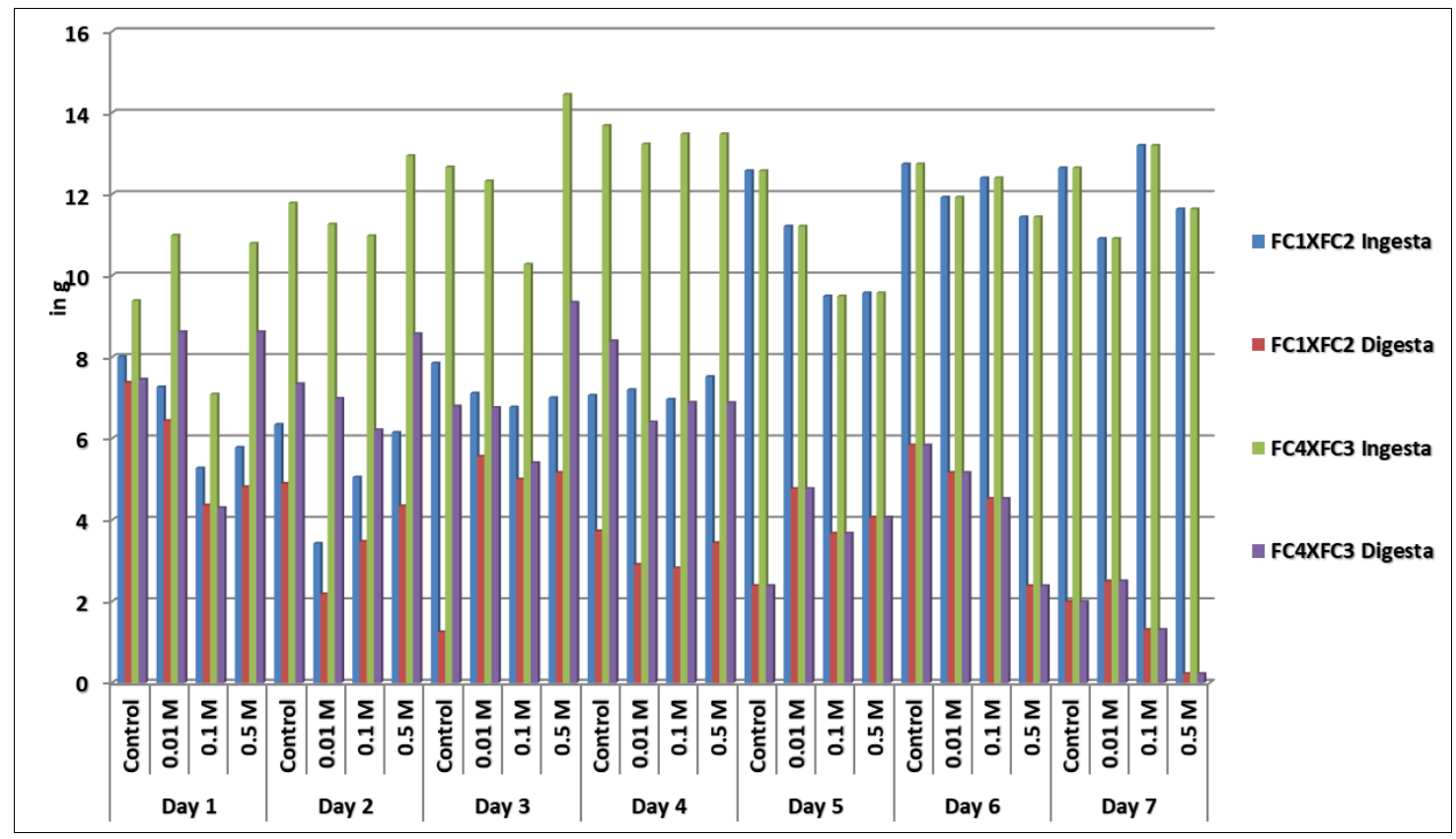

Fig 1: Changes in the food ingesta and digesta of silkworm hybrids treated with different doses of cholesterol during $5^{\text {th }}$ instar

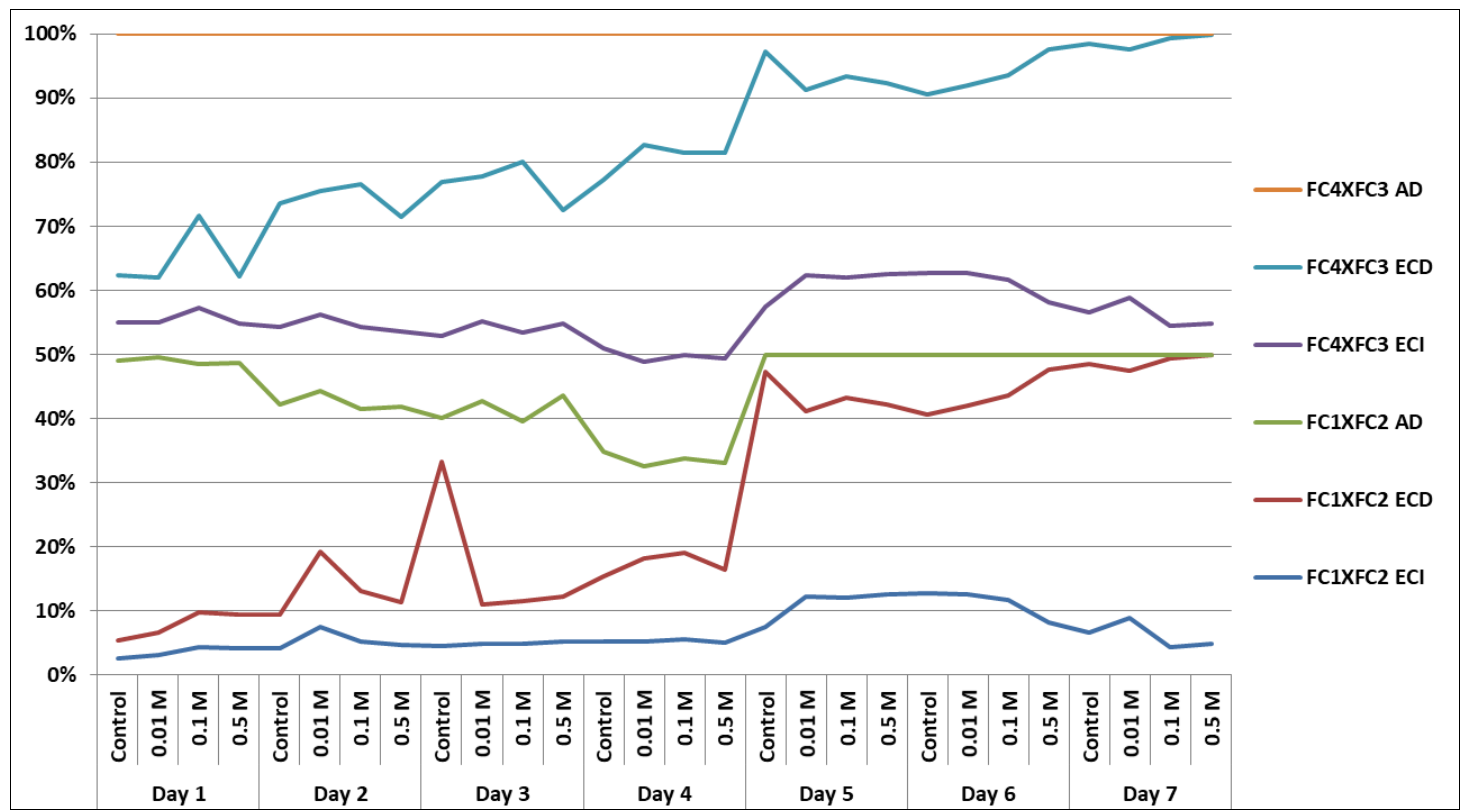

Fig 2: Changes in the efficiency of conversion of ingesta, efficiency of conversion of digesta and approximate digestibility of two silkworm hybrids treated with different doses of cholesterol during $5^{\text {th }}$ instar 


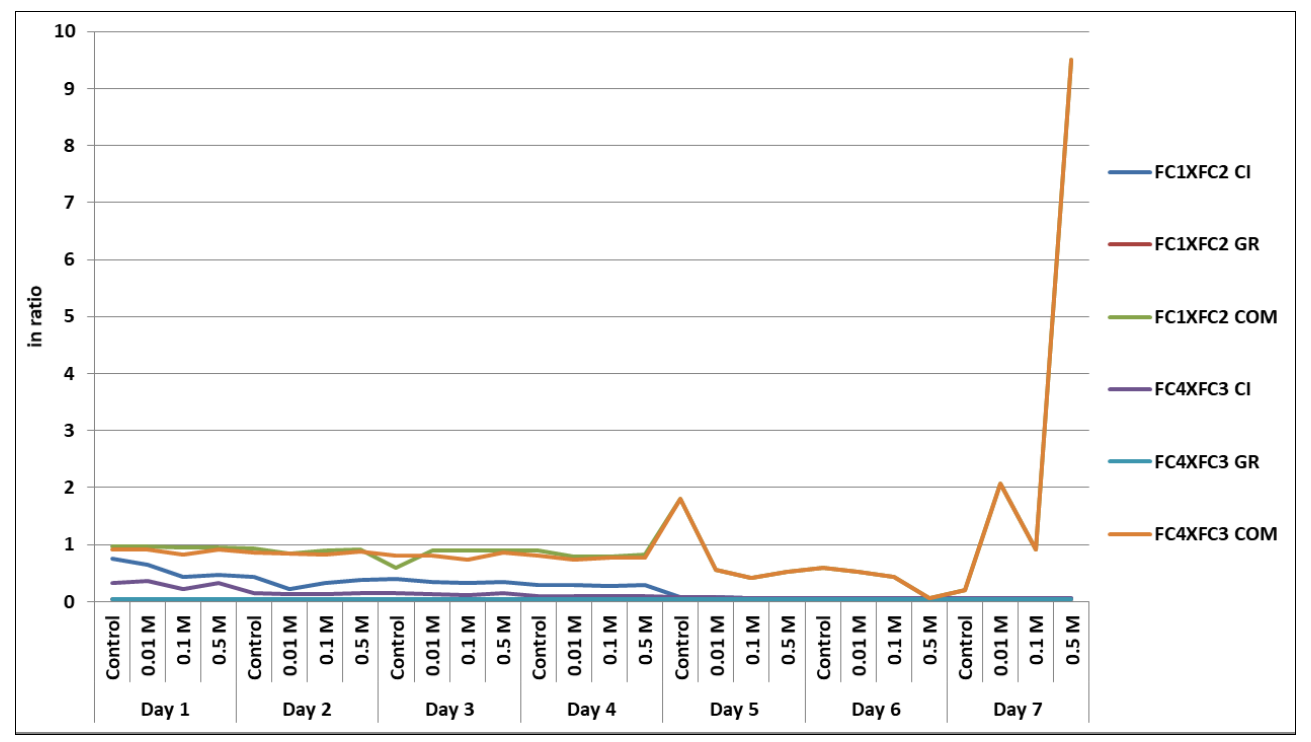

Fig 3: Changes in the consumption index, growth rate and coefficient of metabolism of silkworm hybrids treated with different doses of cholesterol during $5^{\text {th }}$ instar

\section{Conclusion}

The maximum in gesta was recorded in $\mathrm{FC}_{1} \mathrm{X} \mathrm{FC}_{2}$ than $\mathrm{FC}_{4} \mathrm{X}$ $\mathrm{FC}_{3}$ hybrid whereas, the digesta also showed a same trend as observed in in gesta, however the comparative evaluation of the digesta were found to be noticed always half of the ingesta. The efficiency of conversion of food ingested, efficiency of conversion of food digested and approximate digestibility enhances above the level of $50 \%$ the day 1 of the $5^{\text {th }}$ instar till the day of spinning $\mathrm{FC}_{4} \mathrm{X} \mathrm{FC}_{3}$ hybrid, whereas the $\mathrm{FC}_{1} \mathrm{X} \mathrm{FC}_{2}$ hybrid exhibits the magnitude of changes not more than level of $50 \%$ throughout the $5^{\text {th }}$ instar larval periods. The consumption index, growth rate and co-efficient of metabolism of the silkworm hybrid treated with cholesterol during $5^{\text {th }}$ instar but the ratio falls within the range of $0-2$ in all the concentration of cholesterol but on $7^{\text {th }}$ day, the consumption index exceeds the ratio up to 9 at $0.1 \mathrm{M}$ concentration of cholesterol treatment.

\section{Acknowledgement}

The authors greatly acknowledge to Department of Studies in Sericulture, University of Mysore, Manasagangothri, and Mysore 570006 for providing facilities to conduct research.

\section{References}

1. Balasundaram, Selvisabhanayakam, V. Mathivanan. Studies on comparative feed efficacy of mulberry leaves MR2 and MR2 treated with Vitamin-C on Bombyx mori (L.) (Lepidoptera: Bombycidae) in relation to larval parameters. J Curr. Sci. 2008; 12(2):31-35.

2. Barton Browne, D. Raubenheimer., Ontogenetic changes in the rate of ingestion and estimates of food consumption in fourth and fifth in star Helicoverpa armigera caterpillars. Journal of Insect Physiology. 2003; 49(1):63-71.

3. Bernays MS, Singer. A rhythm underlying feeding behavior in a highly polyphagous caterpillar. Physiological Entomology. 1998; 23:295-302.

4. Bernays HA. Woods, foraging in nature by larvae of Manduca sexta influenced by an endogenous oscillation. Journal of Insect Physiology. 2000; 46: 825-836.

5. Bowdan, The effect of deprivation on the microstructure of feeding by the tobacco hornworm caterpillar. Journal of Insect Behaviour, 1988, 131-50.

6. Etebari, M. and Fazilati, Effect of feeding on mulberry's supplementary leaves with multi-mineral in some biological and biochemical characteristics of silkworm (Bombyx mori). J Sci. Technol. Agric. Natur. Resour. 2003; 7:233-244.

7. Etebari B, Kaliwal L, Matindoost, Supplementation of mulberry leaves in sericulture, theoretical and applied aspects. Int. J Indust. Entomol. 2004; 9:14-28.

8. Hamamura Y, Naito K. Food selection by silkworm larvae Bombyx mori. Nature. 1961; 190(3):879-880.

9. Horie Y, Watanabe H, Ito T. Nutrition of the silkworm, Bombyx mori - XIV. Further studies on the requirements for B vitamins. Bull. Seric. Exp. Sta, Tokyo. 1966; 20:393-409.

10. Ichimasa Y. Sterol accumulation in developing ovaries of the silkworm Bombyx mori in relation to diapause hormone. J Insect. Physoil. 1976; 22:1071-1074.

11. Koul, Relationship among leaf consumption, body weight and silk production in Bombyx mori L. Agric. Sci. Digest. 1989; 9(4):208-209.

12. Krishnaswamy S. New technology of silkworm rearing. Bulletin. CSR\&TI, Mysore, India. 1978; 2:1-24.

13. Magadum SB, Ramadevi OK, Shivashankar N, Datta RK. Nutritional indices in some bivoltine breed of silkworm, Bombyx mori L. Indian J Sericol. 1996; 35:95-98.

14. Maynard LA, Loosli JK. McGraw- Hill Book Co, 1962, 533.

15. Nagaraju J. Application of genetic principles for improving silk production. Curr. Sci. 2002; 83:409-414.

16. Nirwani RB, Kaliwal BB. Effect of thiamine on commercial traits and biochemical contents of the fat body and haemolymph in the silkworm, Bombyx mori L. Sericologia. 1998; 38:639-646.

17. Rath SS, Prasad BC, Sinha BRP. Food utilization efficiency in fifth instar larvae of Antheraea mylitta (Lepidoptera: Saturniidae) infected with Nosema sp. and its effect on reproductive potential and silk production. $\mathbf{J}$ Invert. Pathol. 2003; 83:1-9.

18. Saha BN, Khan AR. The growth and development of the silkworm, Bombyx mori L. on feed supplemented with nicotinic acid. Bangladesh J Life Sci. 1996, 1103-109.

19. Waldbauer GP. The consumption and utilization of food by insects. Advances in insect physiology. 1968; 5:229288. 